\title{
Effect of mHealth on Blood Glucose Control in Pregnancies Complicated by Diabetes: A Systematic Review
}

Taylor A. Ricci, BSc Student [1], Husain A. Akbar, BSc Student [1]
[1] Department of Life Sciences, Queen's University, Kingston, Ontario, Canada, K7L 3N6

*Corresponding Author: taylor.ricci@queensu.ca

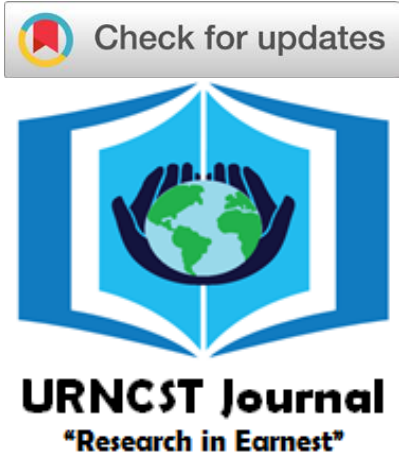

\begin{abstract}
Introduction: For women with diabetes, optimizing blood glucose is critical during pregnancy to reduce the risk of complications. Mobile health interventions contribute to improved blood glucose control among non-pregnant adults with diabetes, but their effect during pregnancy is not known.

Methods: We conducted a systematic review to determine the effect of mobile health interventions on blood glucose control among women with type 1 diabetes, type 2 diabetes, and gestational diabetes mellitus during pregnancy. We searched the databases Ovid Medline, Ovid Embase, The Cochrane Central Register of Controlled Trials, and ClinicalTrials.gov from inception to August 2020. We did not apply limitations to our search. We also examined grey literature and reviewed the reference lists of relevant articles. Studies were eligible for inclusion if they used a randomized controlled trial to determine the effect of mobile health on blood glucose control among women with type 1 diabetes, type 2 diabetes, or gestational diabetes mellitus during pregnancy. A modified version of the Cochrane Randomized Control Trial data collection form and the Template for Intervention Description and Replication checklist guided data collection. We used the Cochrane Risk of Bias 2.0 tool and the Grading of Recommendations Assessment, Development, and Evaluation approach to assess the risk of bias and certainty of the evidence, respectively. Cochrane guidelines for Synthesis Without Meta-analysis informed data analysis.

Results: We included four randomized controlled trials on the effect of mobile health as compared to usual care on blood glucose control among women with gestational diabetes mellitus.

Discussion: Only one of the four trials reported a positive effect direction, while the remaining studies reported negative or conflicting/unclear effects. The certainty of the evidence was low.

Conclusion: Mobile health may have little to no effect on blood glucose control among women with gestational diabetes mellitus. Our synthesis revealed non-significant results and the certainty of evidence was low. However, as there is a current scarcity of randomized controlled trials, future studies are warranted to explore this topic, particularly given the emphasis on virtual healthcare as a result of the COVID-19 pandemic.
\end{abstract}

Keywords: pregnancy; diabetes; telemedicine; systematic review

\section{Introduction}

Background and Rationale

Pregnancy is accompanied by many potential risks. Women who have pre-existing type 1 diabetes or type 2 diabetes or who are diagnosed with gestational diabetes mellitus are at an even greater risk, as studies show that women with diabetes have higher rates of pregnancy complications compared to the general population [1-6]. Close monitoring of blood glucose to achieve glycemic targets is imperative throughout pregnancy as uncontrolled hyperglycemia is associated with increased pregnancy complications, including higher rates of perinatal mortality and congenital malformations $[7,8]$. To reduce hyperglycemia and achieve glycemic targets, women with type 1 diabetes are advised to continue existing management, including frequent self-monitoring of blood glucose and insulin administration [1, 9-11]. Teratogenic effects of any medication, including oral hypoglycemic agents, taken during pregnancy must be minimized. As insulin does not pass the placenta-blood barrier and is safe during pregnancy, insulin is initiated for women with type 2 diabetes at the onset of pregnancy as a means of achieving glycemic targets [1, 9-11]. For women who develop gestational diabetes mellitus, a majority can self-manage through lifestyle changes alone. However, in some cases, insulin must also be initiated to achieve optimal glycemic targets $[1,9,10,12]$. In all cases, women are advised on the importance of self-monitoring blood glucose (SMBG) [911]. Canadian guidelines emphasize the importance of diabetes self-management education and support to improve glycemic control and reduce the risk of maternal and infant complications [1]. Evidence indicates that 
UNDERGRADUATE RESEARCH IN NATURAL AND CLINICAL SCIENCE AND TECHNOLOGY (URNCST) JOURNAL Read more URNCST Journal articles and submit your own today at: https://www.urncst.com

patients who frequently self-monitor their blood glucose and make other lifestyle changes to proactively decrease hyperglycemia can reduce the risk of complications for themselves and their infant [1, 13]. Multiple studies have demonstrated that patients who perform frequent SMBG have better metabolic control and diabetes outcomes compared to those who perform SMBG infrequently [14]. There is substantial evidence that indicates highly regulated glycemic control reduces the risk of complications from diabetes, and this control is especially imperative during pregnancy [15-19]. Interventions that facilitate SMBG have the potential to improve blood glucose control and reduce the risk of diabetes-related pregnancy complications [20].

Mobile health (mHealth) is a self-management support tool involving the practice of medicine enriched by the power of technology and supported by mobile phone devices [21]. The emerging field of mHealth has begun to break down the systemic barriers of healthcare through the use of smartphone applications that support effective patient self-management, including self-monitoring of blood glucose, among other things. mHealth provides an opportunity to alleviate the massive global healthcare challenges and economic burdens associated with diabetes and its long-term complications [20]. Due to the ubiquitous nature of smartphone technology, mHealth applications provide an opportunity to facilitate and incentivize patient engagement in the management of diabetes and allow for interactive communication with healthcare providers without the time and cost of a clinical appointment. For pregnant women, there is the potential that mHealth applications may be able to facilitate diabetes selfmanagement and contribute to minimizing the risks associated with diabetes in pregnancy. The use of mHealth could also lower the burden on the healthcare system [22]. A recent evaluation of systematic reviews of randomized controlled trials showed that compared to usual care, mHealth interventions lead to statistically significant and clinically important improvements in glycemic control among non-pregnant adults with diabetes when compared to the usual antenatal care practices [23]. Yet, to date, the effect of mHealth interventions on blood glucose control during pregnancy across the spectrum of women with preexisting diabetes and gestational diabetes mellitus has not been explored in a systematic review. Thus, given the high level of evidence among non-pregnant adults with diabetes, we hypothesize that mHealth interventions may result in improved blood glucose control among women with diabetes during pregnancy.

\section{$\underline{\text { Objective }}$}

The objective of this systematic review is to determine the effect of mHealth interventions on blood glucose control among women with type 1 diabetes, type 2 diabetes, and gestational diabetes mellitus during pregnancy.

\section{Methods}

The Cochrane Handbook for the Conduct of Systematic Reviews and Meta-Analyses [24], the Synthesis Without Meta-Analysis in Systematic Reviews: Reporting Guideline [25], and the Preferred Reporting Items for Systematic Reviews and Meta-Analyses [26] guided the conduct and reporting of this review, respectively.

$\underline{\text { Protocol and Registration }}$

We did not publish a protocol for this review.

Information Sources and Search

We searched the electronic databases Ovid Medline, Ovid Embase, The Cochrane Central Register of Controlled Trials, and ClinicalTrials.gov from inception up to August 2020. The search strategies employed a combination of the following terms, modified as appropriate for each database: "pregnancy," "mHealth," and "diabetes mellitus" and were conducted without any limitations. Additionally, grey literature publications were searched, and the reference list of relevant articles and those pulled for full-text were also reviewed. Table 1 provides the electronic search strategy for the Ovid Medline search. The search strategies for the other databases are available upon request.

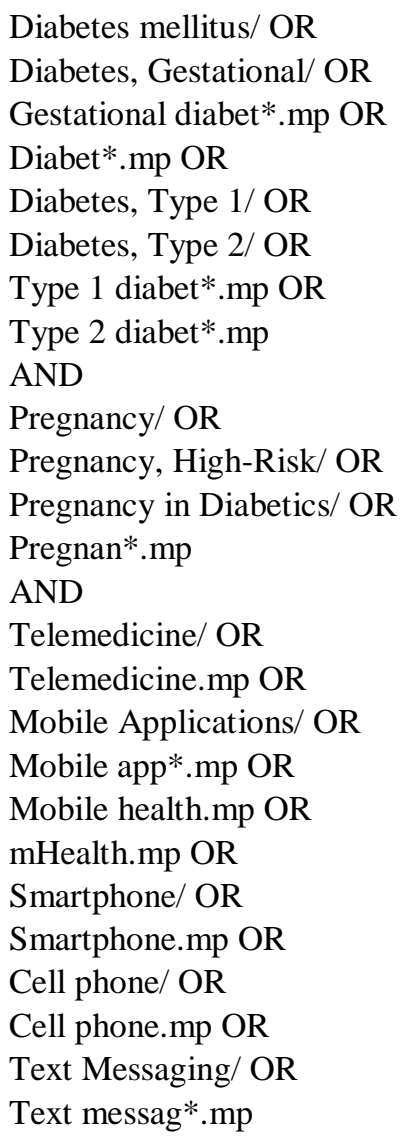

Table 1. Ovid Medline Search Strategy 
UNDERGRADUATE RESEARCH IN NATURAL AND CLINICAL SCIENCE AND TECHNOLOGY (URNCST) JOURNAL Read more URNCST Journal articles and submit your own today at: https://www.urncst.com

\section{Eligibility Criteria and Study Selection}

We exported all citations to Zotero for deduplication and screening by two independent reviewers (TR and HA). Inclusion criteria at the title and abstract stage included studies focused on pregnancy and diabetes. Following title and abstract screening, eligible studies were reviewed at the full-text level. The inclusion criteria at this stage included randomized controlled trials focused on mHealth interventions for women with diabetes in pregnancy. Any disagreements were resolved through discussion or by consultation with a third reviewer.

\section{Data Collection Process and Data Items}

A modified version of the Cochrane Randomized Control Trial [24] data collection form and the Template for Intervention Description and Replication checklist [27] guided data collection. The collection process was first piloted among all reviewers to determine usability and efficacy. Duplicate data extraction was performed by two reviewers (TR and $\mathrm{HA}$ ) with the inclusion of a third reviewer to reach consensus if required. Guided by these respective documents, we extracted information about the study author, funding source, study year and design as well as information on the population demographic, such as age, gestational age, and socioeconomic background. Intervention methodology to the degree of replication was also collected. The extraction of outcome data was focused on blood glucose control. Due to the diversity in the literature regarding the reporting of outcomes related to blood glucose control, we will use the terminology "blood glucose control" to represent our outcome of interest. In this review, in order to include as many studies and outcomes as possible, "blood glucose control" as an outcome will include $\mathrm{A} 1 \mathrm{C}$, mean pre-prandial, postprandial, and fasting blood glucose, percentage of on- and off-target blood glucose levels, post-partum oral glucose tolerance tests result for patients with gestational diabetes mellitus, and the need for medication during pregnancy for patients with gestational diabetes (including oral hypoglycemics and/or insulin). If the case arose where authors reported blood glucose control using other outcome measures than what we have indicated a priori, we planned to at this time to discuss whether or not to include such outcome data.

$\underline{\text { Risk of Bias in Individual Studies }}$

The risk of bias assessment of individual studies was completed using the Cochrane Risk of Bias 2.0 tool [28].
Risk of bias assessment was performed in duplicate by two reviewers (TR and HA) with the inclusion of a third if needed to reach consensus.

Synthesis of Results

We planned to conduct a meta-analysis of the effect of mHealth interventions on blood glucose control, this was not possible due to a lack of required data presented in the included studies. Only one of the included studies reported the measures of variance required to conduct of a metaanalysis (standard deviation). To remedy this, we attempted to use a calculator tool by Cochrane Training to calculate the missing standard deviations. Unfortunately, the tool cannot calculate standard deviation if the study confidence intervals, which are used in the calculation, are not symmetrical about the mean, indicating that they may have been calculated on transformed values. This was the case when we attempted to calculate the missing standard deviations. Therefore, we conducted a synthesis without meta-analysis informed by the Synthesis Without MetaAnalysis in Systematic Reviews: Reporting Guideline [25]. Data was grouped based on outcomes that assessed blood glucose control. These outcomes included the use of medication for gestational diabetes mellitus (metformin, insulin, or both), results of the postpartum Oral Glucose Tolerance Test, glycated hemoglobin A1C (A1C) before delivery, percentage of on- and off-target glucose measurements, mean blood glucose, rate of change in glycemia (mmol/L/28 days), and rate of change in A1C. We chose effect direction as our standardized metric

\section{Assessment of the Quality (Certainty) of Evidence}

We used the Grading of Recommendations Assessment, Development, and Evaluation approach [29] to assess the certainty of the evidence.

\section{Results}

Study Selection

From the database and grey literature searches, we obtained 474 articles of which 154 were removed following deduplication, resulting in 320 articles that were screened at the title and abstract level. This yielded 60 studies for fulltext review. However, five were excluded as we could not retrieve the full-text. As such, 55 articles were assessed for eligibility at the full-text level. A total of four randomized controlled trials were included in our final review [30-33]. Figure 1 provides the flow of the study selection process. 
UNDERGRADUATE RESEARCH IN NATURAL AND CLINICAL SCIENCE AND TECHNOLOGY (URNCST) JOURNAL Read more URNCST Journal articles and submit your own today at: https://www.urncst.com

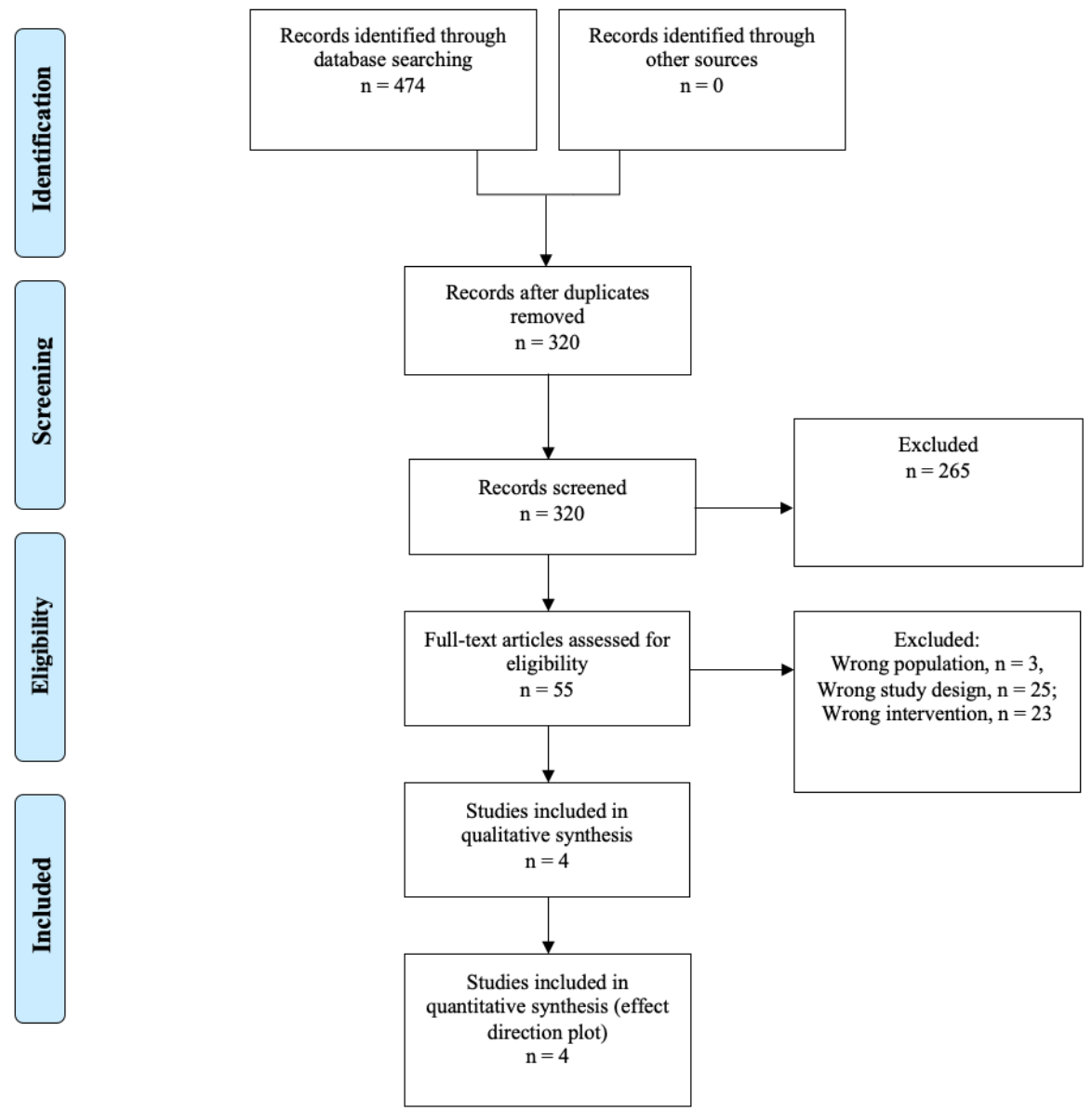

Figure 1. Flow Diagram of the Study Selection Process

\section{$\underline{\text { Study Characteristics }}$}

\section{Setting}

The included studies were conducted in China, Israel, Norway, and the United Kingdom.

\section{Participants}

Although our eligibility criteria included pregnant women with type 1 diabetes, type 2 diabetes, and gestational diabetes mellitus, the included studies consisted of only pregnant women diagnosed with gestational diabetes mellitus.

\section{Interventions}

mHealth applications were the intervention of interest in the included studies. Although all studies used a different mHealth application, each had a similar premise, offering participants a platform to track health behaviours (physical activity, diet, blood glucose levels) and facilitate communication with their healthcare provider during pregnancy.

\section{Comparisons}

The comparison in all included studies was usual antenatal care delivered in the outpatient clinic setting. The level of detail regarding usual care varied across the included studies. Available information indicated that usual antenatal care was comprised of counseling related to maintenance of a healthy diet, recommendations regarding regular physical activity, and instruction on SMBG. Usual care also included standard antenatal surveillance such as monitoring for hypertension and proteinuria, non-stress tests and biophysical profiles.

\section{Outcomes}

The outcomes of interest were those that related to blood glucose control. The measures related to the outcome of blood glucose control reported varied and included the use of medication for gestational diabetes mellitus (metformin, insulin, or both), results of the postpartum Oral Glucose Tolerance Test, glycated hemoglobin A1C (A1C) before delivery, percentage of on- and off-target glucose measurements, mean blood glucose, rate of change in glycemia (mmol/L/28 days), and rate of change in A1C. 
UNDERGRADUATE RESEARCH IN NATURAL AND CLINICAL SCIENCE AND TECHNOLOGY (URNCST) JOURNAL

Read more URNCST Journal articles and submit your own today at: https://www.urncst.com

\begin{tabular}{|c|c|c|c|c|c|c|c|c|c|}
\hline & & & Population & & & Intervention & Control & & Outcome \\
\hline $\begin{array}{l}\text { Author } \\
{[\text { Ref], }} \\
\text { Year, } \\
\text { Country }\end{array}$ & $\begin{array}{c}\text { Diabetes } \\
\text { Type }\end{array}$ & $\begin{array}{c}\text { Diabetes Medications } \\
\mathbf{N}(\%)\end{array}$ & $\begin{array}{l}\text { A1C* } \\
\text { Mean } \\
\% \text { (SD) }\end{array}$ & $\begin{array}{c}\text { Age, } \\
\text { Mean years } \\
\text { (SD) or } \mathrm{N}[\%]\end{array}$ & $\begin{array}{c}\text { Comorbidities, } \\
\mathbf{N}(\%)\end{array}$ & $\begin{array}{c}\text { mHealth } \\
\text { App, } \\
\text { N participants }\end{array}$ & $\begin{array}{l}\text { Usual Care, } \\
\text { N Participants }\end{array}$ & Follow-Up & $\begin{array}{l}\text { Assessed Outcomes Related } \\
\text { to Blood Glucose }\end{array}$ \\
\hline \multirow[t]{6}{*}{$\begin{array}{l}\text { Borgen [12] } \\
2019, \\
\text { Norway }\end{array}$} & \multirow[t]{6}{*}{ GDM } & $\stackrel{\text { Intervention }}{\text { Metformin, } 25(10.7 \%)}$ & $N / R$ & $\frac{\text { Intervention }}{\leq 29,30[26.1]}$ & $N / R$ & \multirow[t]{6}{*}{$\begin{array}{l}\text { Pregnant }+, \\
\quad 112\end{array}$} & \multirow{6}{*}{$\begin{array}{c}\text { Midwife and/or } \\
\text { diabetes nurse } \\
\text { consultations } \\
\text { every two weeks, } \\
121\end{array}$} & \multirow[t]{6}{*}{$\begin{array}{l}3 \text { months } \\
\text { postpartum }\end{array}$} & \multirow{6}{*}{$\begin{array}{l}\text { Treatment with insulin and/or metformin } \\
\text { 2-hour OGTT } \\
3 \text { months postpartum } \\
\text { 2-hour OGTT change from baseline to } 3 \\
\text { months postpartum }\end{array}$} \\
\hline & & Insulin, $45(19.3 \%)$ & & $30-37,66[57.4]$ & & & & & \\
\hline & & $\begin{array}{c}\text { Insulin and Metformin } \\
12(5.2 \%)\end{array}$ & & $\geq 38,19[16.5]$ & & & & & \\
\hline & & $\stackrel{\text { Control }}{\text { Metformin, } 15(12.4 \%)}$ & & $\leq 29,27[22.0]$ & & & & & \\
\hline & & Insulin, 24 (19.8\%) & & $30-37,62[50.4]$ & & & & & \\
\hline & & $\begin{array}{c}\text { Insulin and Metformin, } \\
4(3.3 \%)\end{array}$ & & $\geq 38,34[27.6]$ & & & & & \\
\hline \multirow[t]{3}{*}{$\begin{array}{l}\text { Guo [13], } \\
2018, \\
\text { China }\end{array}$} & \multirow[t]{3}{*}{ GDM } & \multirow[t]{3}{*}{$N / R$} & $\frac{\text { Intervention }}{6.0(0.4)}$ & $\frac{\text { Intervention }}{31.2(4.1)}$ & $\begin{array}{l}\text { Hypertension } \\
\text { Intervention } \\
1(1.5 \%)\end{array}$ & \multirow[t]{3}{*}{$\begin{array}{l}\text { Dnurse, } \\
\quad 64\end{array}$} & \multirow[t]{3}{*}{$\begin{array}{l}\text { Outpatient } \\
\text { treatment, } \\
60\end{array}$} & \multirow[t]{3}{*}{$\begin{array}{l}3 \text { months } \\
\text { postpartum }\end{array}$} & \multirow{3}{*}{$\begin{array}{l}\text { A1C before delivery } \\
\% \text { off-target fasting glucose } \\
\% \text { off-target } 2 \text {-hour postprandial glucose } \\
\text { Fasting OGTT at } 3 \text { months postpartum } \\
\text { 2-hour OGTT at } 3 \text { months postpartum }\end{array}$} \\
\hline & & & Control & Control & & & & & \\
\hline & & & $\overline{5.9(0.3)}$ & $30.6(3.1)$ & $\begin{array}{l}\text { Control } \\
1(1.6 \%)\end{array}$ & & & & \\
\hline \multirow{3}{*}{$\begin{array}{l}\text { Miremberg } \\
{[14],} \\
2018 \\
\text { Israel }\end{array}$} & \multirow[t]{3}{*}{ GDM } & Intervention & Intervention & \multirow{3}{*}{$\begin{array}{c}\mathrm{N} / \mathrm{R} \\
\text { Inclusion } \\
\text { criteria: } 18-45 \\
\text { years }\end{array}$} & Hypertension & Glucose & \multirow{3}{*}{$\begin{array}{l}\text { Control group, } \\
\quad 60\end{array}$} & \multirow[t]{3}{*}{ Delivery } & \multirow{3}{*}{$\begin{array}{l}\text { Mean blood glucose } \\
\% \text { off-target } 1 \text {-hour fasting glucose } \\
\% \text { off-target fasting glucose measurement } \\
\text { Treatment with insulin }\end{array}$} \\
\hline & & Insulin, $8(13.3 \%)$ & $5.2(0.33)$ & & $\frac{\text { Intervention }}{5(8.3 \%)}$ & $\begin{array}{l}\text { Buddy, } \\
\quad 60\end{array}$ & & & \\
\hline & & $\underset{\text { Insulin, } 18(30.0 \%)}{\text { Control }}$ & $\frac{\text { Control }}{5.2(0.4)}$ & & $\begin{array}{l}\text { Control } \\
1(1.7 \%)\end{array}$ & & & & \\
\hline \multirow{4}{*}{$\begin{array}{l}\text { Mackillop } \\
{[15],} \\
2018 \\
\text { United } \\
\text { Kingdom }\end{array}$} & \multirow[t]{4}{*}{ GDM } & Intervention & $\underline{\text { Intervention }}$ & Intervention & Hypertension & \multirow{4}{*}{$\begin{array}{l}\text { GDm-health, } \\
\quad 101\end{array}$} & \multirow{4}{*}{$\begin{array}{c}\text { Standard clinic } \\
\text { care, } \\
102\end{array}$} & \multirow[t]{4}{*}{ Delivery } & \multirow{4}{*}{$\begin{array}{l}\text { Rate of change in glycemia (mmol/L/28 days) } \\
\text { Rate of change of A1C } \\
\% \text { fasting blood glucose on target within } 4 \\
\text { weeks of randomization } \\
\% \text { blood glucose postprandial observations on } \\
\text { target within } 4 \text { weeks of randomization } \\
\% \text { blood glucose fasting observations on } \\
\text { target between } 4 \text { and } 8 \text { weeks of } \\
\text { randomization } \\
\% \text { blood glucose postprandial observations on } \\
\text { target between } 4 \text { and } 8 \text { weeks of } \\
\text { randomization }\end{array}$} \\
\hline & & Metformin, $45(44.6 \%)$ & $\overline{5.42(0.34)}$ & $33 / 9(5.5)$ & $\frac{\text { Intervention }}{2(2.0 \%)}$ & & & & \\
\hline & & Control & Control & Control & Control & & & & \\
\hline & & Metformin, 57 (55.9\%) & $5 . \overline{39(0.35)}$ & $33.0(5.6)$ & $6(5.9 \%)$ & & & & \\
\hline
\end{tabular}

*At diagnosis, recruitment, or randomization. Application, app; N/R, not reported; Oral Glucose Tolerance Test, OGTT

Ricci et al. | URNCST Journal (2021): Volume 5, Issue 5

Page 5 of 12

DOI Link: https://doi.org/10.26685/urncst.218 
UNDERGRADUATE RESEARCH IN NATURAL AND CLINICAL SCIENCE AND TECHNOLOGY (URNCST) JOURNAL

Read more URNCST Journal articles and submit your own today at: https://www.urncst.com

Table 3. Description of mHealth Interventions Based on the TIDieR Criteria of the Included Randomized Controlled Trials

Trials

\begin{tabular}{ll}
\hline TIDieR Criteria & Borgen, 2019 [12] \\
\hline Name & Pregnancy+ \\
Why? & $\begin{array}{l}\text { mHealth may serve as a personalized tool to } \\
\text { facilitate improved diabetes self-management in } \\
\text { pregnancies complicated by gestational } \\
\text { diabetes. }\end{array}$ \\
What? & $\begin{array}{l}\text { Intervention participants downloaded the } \\
\text { Pregnant+ app on their smartphone and } \\
\text { communicated blood glucose data with and } \\
\text { received feedback from healthcare providers. } \\
\text { Education provided on the app focused on blood } \\
\text { glucose, exercise, diet, and diabetes information. }\end{array}$
\end{tabular}

Guo, $2018[13]$

Miremberg, 2018 [14]

Mackillop, 2018 [15]

Dnurse

Who provided? Midwives and/or diabetes nurses.

Strict control of blood glucose can reduce the rate of adverse perinatal outcomes. Mobile medical apps may increase patient compliance and cooperation.

Intervention participants downloaded the Dnurse app on their smartphone and used it to communicate blood glucose data to and receive feedback from their healthcare provider. Education provided on the app focused on diet, exercise, and diabetes medication.

Educational nurses and physicians.

The intervention was delivered via the Pregnant smartphone app, which was a supplement to usual care appointments every second week. Participants could record mantally or transfer automatically via Bluetooth blood glucose data the app. Participants col

Where?

The app was available anytime from the smartphone.

When/how Participants began using the app upon diabetes much? diagnosis and study enrollment. It was available for use until the participant gave birth.

Blood glucose feedback was individualized. Participants could also select one of three different food cultures identified by language (Norwegian, Urdu, or Somali) and receive culturally adapted dietary information.

Modifications? No modifications to the intervention occurred. How well?

Analytical data on the usage of the application was not collected to maintain participant privacy. However, 34 women in the intervention group and 41 women in the control group did not complete the OGTT
(primary outcome).
The intervention was delivered via the smartphone app, which was a supplement to usual care. Participants recorded blood glucose and in and charts, and transmitted them the healthcare answered questions nightly between 7 and $9 \mathrm{pm}$.

The app was available anytime from the smartphone.

The app was downloaded upon diabetes diagnosis, between 24 to 28 weeks' gestation, birth.

Blood glucose feedback was individualized. Participants were also given personalized answers to questions posed to the education question sessions.

No modifications to the intervention occurred.

Participant compliance (the actual blood glucose measurements, divided by the instructed measurements, multiplied by 100 ) was $83.3 \%$ in the intervention group. and was used daily until the participant gave nurse during the nightly instructional and

\section{Glucose Buddy}

mHealth may promote tight glycemic control, increase patient compliance, and improve perinatal outcomes for women with gestational diabetes.

Intervention participants installed the Glucose Buddy app on their smartphone and used it to communicate blood glucose data with and receive feedback from their healthcare provider. Dietary information and opportunity to ask questions was also provided.

Physicians, dieticians, and nurses.

Participants recorded blood glucose data on the app and transmitted it daily to the healthcare who provided daily feedback. This included positive messages, dietary tips and insulin do adjustments. They could also ask questions receive immediate answers.

The app was available anytime from the smartphone.

The app was downloaded upon study recruitment at $<34$ weeks' gestation was used until the participant gave birth.

Feedback from healthcare providers and answers to participant questions were personalized.

No modifications to the intervention occurred. Participant compliance (actual blood glucose measurements, divided by instructed

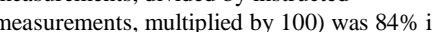
the intervention group. ack from healthcare providers wa individualized to each participant.

GDm-health

mHealth-based real-time blood glucose management may improve hyperglycemia management and outcomes for women with gestational diabetes.

Intervention participants were loaned a mobile phone with the GDm-health app pre-installed. Blood glucose data was recorded and transmitted to healthcare providers who communicated diet and medication adjustments via the app.

Diabetes midwives.

Participants recorded, tagged, and reviewed blood glucose data that was automatically transmitted to a secure website. Healthcare providers reviewed this data three times per week and provided feedback regarding diet recommendations and medication adjustments as well as messages of encouragement.

The app was available anytime from the smartphone.

The app was downloaded upon study recruitment at $<34$ weeks' gestation was used until the participant gave birth.

\section{No modifications to the intervention occurred}

Seventy-eight of 98 participants in the expected number of blood glucose readings. 
UNDERGRADUATE RESEARCH IN NATURAL AND CLINICAL SCIENCE AND TECHNOLOGY (URNCST) JOURNAL
Read more URNCST Journal articles and submit your own today at: $\underline{\text { https://www.urncst.com }}$

$\underline{\text { Risk of Bias in Individual Studies }}$

An assessment of the risk of bias was conducted using the Cochrane Risk of Bias 2.0 tool. Figures 2 and 3 provide a visual summary of the results of the risk of bias assessment. All four included studies were judged to have a low risk of bias. For bias arising from the randomization process, all included trials used a random method of group allocation, all trials either concealed or likely concealed allocation until participants were assigned to the intervention or control, and none of the trials reported baseline differences between groups that suggested a problem with randomization. Regarding the domain of bias due to deviations from intended interventions, in all trials the participants and those delivering the intervention were aware of intervention assignment. We were unable to judge whether deviations from the intended intervention arose because of the experimental context as none of the trials reported information regarding adherence in either the intervention or control groups. For the domain of risk of bias due to missing outcome data, only one study reported data missing from a significant number of participants $(n=75)$ for the outcomes of 2-hour Oral Glucose Tolerance Test at three months postpartum and 2-hour Oral Glucose Tolerance Test change from baseline to three months postpartum [30]. However, the number of participants with missing data was similar between the intervention and control group (34 compared to 41) and we concluded that this was unlikely to have biased the study findings in favour of the intervention as the study outcomes were nonsignificant. We had no concerns for risk of bias due to measurement of the outcome or selection of the reported result.

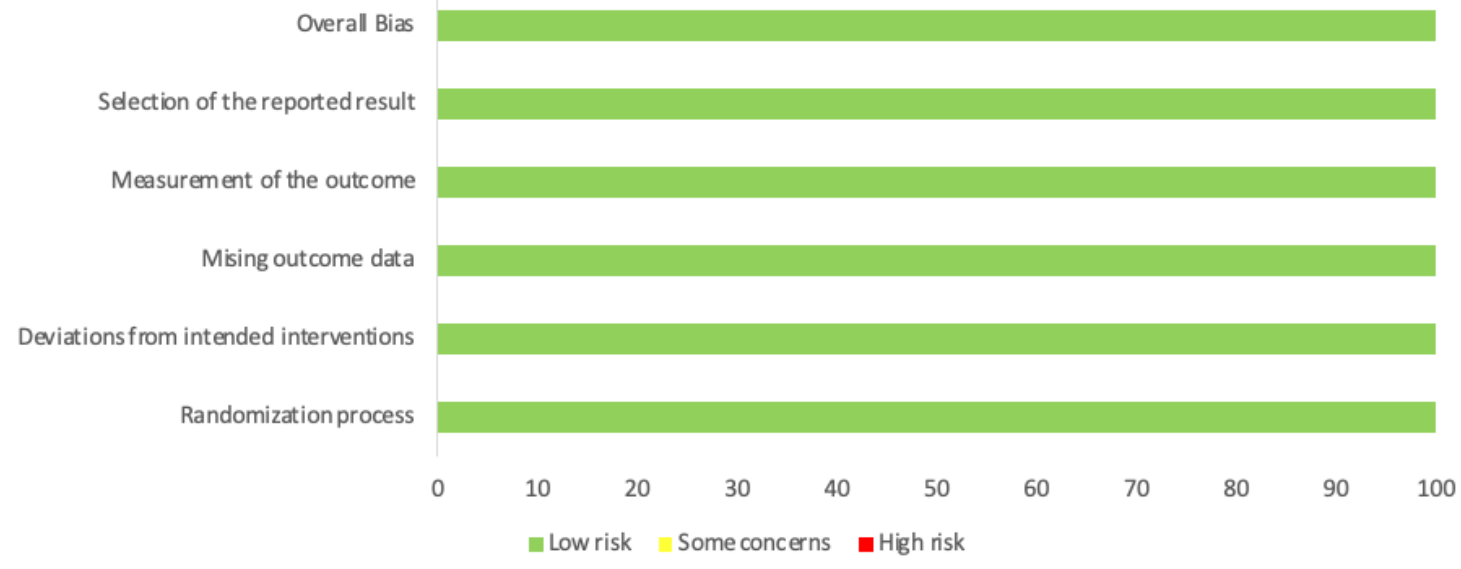

Figure 2. Risk of Bias graph: review authors' judgements about each risk of bias item presented as percentages across studies
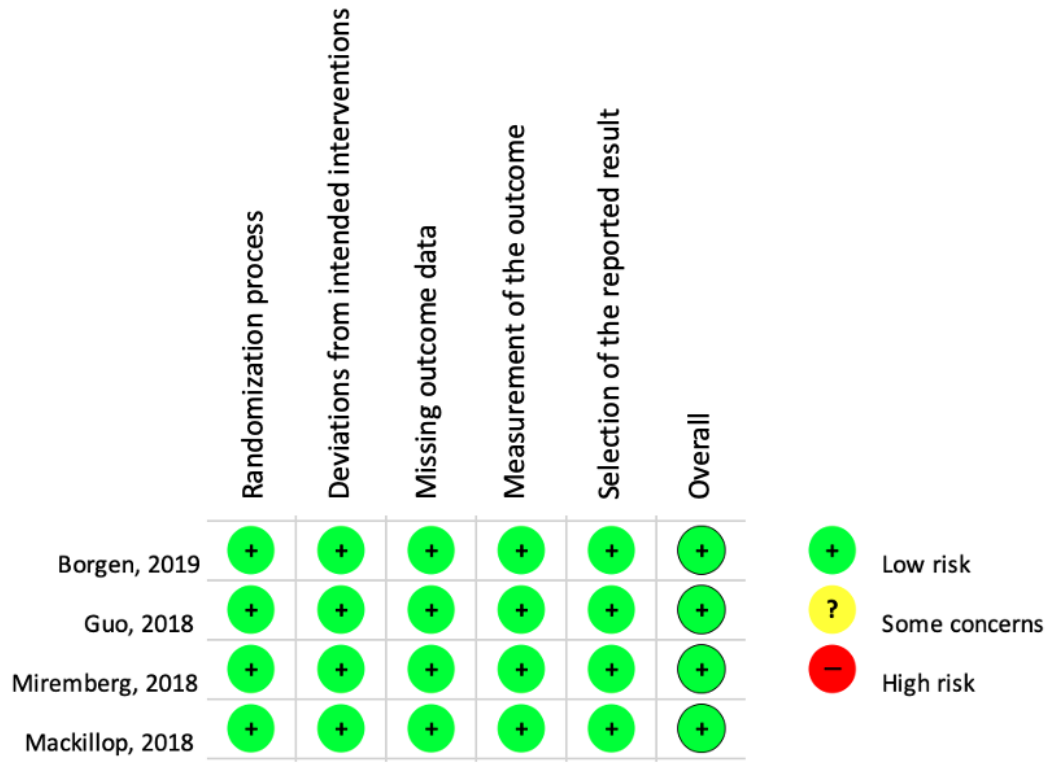

Figure 3. Risk of bias summary: review authors' judgements about each risk of bias item for each included study

Ricci et al. | URNCST Journal (2021): Volume 5, Issue 5

DOI Link: https://doi.org/10.26685/urncst.218 
UNDERGRADUATE RESEARCH IN NATURAL AND CLINICAL SCIENCE AND TECHNOLOGY (URNCST) JOURNAL Read more URNCST Journal articles and submit your own today at: https://www.urncst.com

Synthesis of Results

Two of the four studies included in our review did not provide data on standard deviations. We attempted to derive the missing values from available data, such as confidence intervals and p-values, using a calculator provided by Cochrane Training [34]. However, we were unable to do so as the calculator indicated that the data appeared to have been transformed and were unsuitable for such calculations. As a meta-analysis was therefore not possible, our synthesis followed the Cochrane guidelines for synthesis without meta-analysis [25]. We prepared an Effect Direction Plot as follows. For each included study, we grouped outcomes that assessed blood glucose control (such as A1C before delivery, percentage of off-target fasting glucose measurement, and others) and combined them into a single outcome domain (blood glucose control). We calculated an overall direction of effect for the outcome of blood glucose control for each study that was based on the proportion of outcomes within the domain that reported statistically significant effects in a given direction.

\section{mHealth versus Usual Care}

Four studies with 685 participants were included in this comparison. For the domain of blood glucose control, only one of the four randomized controlled trials reported a positive effect direction [32], with the remaining three studies reporting negative or conflicting/unclear effects $[30,31,33]$.

\begin{tabular}{|l|l|l|}
\hline Study Author and Year & Study design & Blood Glucose Control \\
\hline Borgen, 2019[12] & RCT & $\nabla^{\mathrm{a}}$ \\
\hline Guo, 2018 [13] & RCT & $\mathbf{}^{\mathrm{b}}$ \\
\hline Miremberg, 2018 [14] & RCT & $\mathbf{\Delta}^{\mathrm{c}}$ \\
\hline Mackillop, 2018 [15] & RCT & $\mathbf{\nabla}^{\mathrm{d}}$ \\
\hline
\end{tabular}

a. Use of medication for GDM (metformin, insulin, or both metformin and insulin); 2-hour OGTT 3 months postpartum; 2-hour OGTT change from baseline to 3 months postpartum

b. A1C before delivery; percentage of off-target fasting glucose measurement; percentage of off-target 2-hour postprandial glucose measurement; Fasting OGTT at 3 months postpartum; 2-hour OGTT at 3 months postpartum

c. Mean blood glucose; percentage of off-target 1 hour fasting glucose measurement; percentage of off-target fasting glucose measurement; insulin treatment

d. Rate of change in glycemia ( $\mathrm{mmol} / \mathrm{L} / 28$ days); rate of change in A1C; percentage of blood glucose fasting observations on target within four weeks of randomization; percentage of blood glucose postprandial observations on target within four weeks of randomization; percentage of blood glucose fasting observations on target between four and eight weeks of randomization; percentage of blood glucose postprandial observations on target between four and eight weeks of randomization

A1C, glycated hemoglobin A1C; GDM, gestational diabetes mellitus; OGTT, oral glucose tolerance test; RCT, randomized controlled trial.

Figure 4. Summary of direction of glycemic control from included studies

Assessment of the Quality (Certainty) of Evidence

The overall quality of the evidence was low [35]. The risk of bias assessments determined that all four trials had a low risk of bias. Therefore, we judged that the risk of bias was not serious. The participants, interventions, and comparators in the included trials were directly comparable to our clinical question. As such, we judged concerns about the indirectness of the evidence as not serious [36]. For imprecision, the total number of participants in the included trials met the threshold of greater than $400(n=695)$. However, as only one study reported a $95 \%$ confidence interval, which included no effect, we judged concerns about imprecision as serious [36]. Therefore, we downgraded the quality of the evidence. For inconsistency, overall, the results showed either a negative or unclear direction of the effect of mHealth interventions on glycemic control among women with gestational diabetes mellitus. Two trials showed a negative effect direction, one showed unclear or uncertain effect direction, and one study showed a positive effect direction. Therefore, we judged the evidence to have serious inconsistencies and downgraded the quality [36]. We did not strongly suspect publication bias as both negative and positive trials have been published and included in our review and our search strategy was comprehensive [36]. 
UNDERGRADUATE RESEARCH IN NATURAL AND CLINICAL SCIENCE AND TECHNOLOGY (URNCST) JOURNAL Read more URNCST Journal articles and submit your own today at: https://www.urncst.com

\section{Discussion}

Summary of Evidence

Our systematic review included four randomized controlled trials that explored the use of mHealth interventions among women with diabetes in pregnancy. The included studies were conducted in diverse geographical and ethnic contexts and the data presented in this review reflects a range of mHealth applications as well as the effect of mHealth on participants of varied sociocultural backgrounds. In general, the mHealth intervention across all studies facilitated the tracking of health behaviors and health data as well as communication between participants and healthcare providers. As the data reported in the included studies was insufficient to conduct a meta-analysis, we performed a synthesis without metaanalysis. This included the construction of an effect direction plot to determine the effect of mHealth compared to usual care on blood glucose control.

The results of our synthesis found that only one of the four included trials reported a positive effect direction, while the others reported effect directions that were negative or unclear. The existing literature focused on the effect of mHealth interventions on blood glucose control among adults with diabetes has been mostly favourable. Among non-pregnant adults with diabetes, a review of systematic reviews found that mHealth interventions contributed to statistically and clinically significant improvements in A1C [37]. For women with diabetes in pregnancy, a meta-analysis of randomized and nonrandomized studies focused on mHealth and web-based interventions found a statistically significant decrease of blood glucose among intervention compared to control participants [38]. It is possible that given the incomplete reporting of data within the small number of randomized controlled trials included in our review, future studies may find results that are more favourable.

Although our aim was to determine the effect of mHealth on blood glucose control during pregnancy across the spectrum of women with diabetes in pregnancy, we were unable to locate any randomized controlled trials that examined the effect of mHealth among women with type 1 diabetes or type 2 diabetes in pregnancy. Therefore, our review only included randomized controlled trials that explored the effect of mHealth on women with gestational diabetes mellitus. As a result, the conclusions of our review may not be applicable to all women with diabetes in pregnancy, limited instead to those with gestational diabetes mellitus.

\section{Implications for Clinical Practice and Research}

The results of our systematic review indicate that the effect of mHealth on glycemic control during a pregnancy complicated by gestational diabetes mellitus are mostly negative or unclear. However, our conclusions are limited given the small number of studies, insufficient reporting of data, and the low certainty of evidence. Other existing literature, among non-pregnant adults and non-randomized studies of women with diabetes in pregnancy, have shown positive results, suggesting that mHealth may contribute to improved blood glucose control [37,38]. Future research is required to explore this further as well as to examine the impact of mHealth interventions among women with type 1 and type 2 diabetes in pregnancy. Other studies have suggested that mHealth may increase access to health information and treatment, particularly for those who fall between the gaps of standard care, such as those with low socioeconomic status or those from rural areas [39]. mHealth may also represent a promising convenient approach for women managing diabetes in pregnancy as literature indicates that mHealth interventions are easy to use and many would consider utilizing mHealth in future pregnancies [32]. Although our review was focused on the effect of mHealth on blood glucose control, the included studies also assessed other outcomes, concluding that mHealth may reduce the frequency of outpatient visits, which may impact healthcare costs [31]. This presents another potential avenue for the direction of future research.

\section{Limitations}

Our systematic review is limited in that it only consisted of four randomized controlled trials. In addition, although data was available across all of the studies regarding our outcome of interest, the included studies determined the effect of mHealth on blood glucose control during pregnancy using a variety of different measures. These measures ranged from A1C before delivery, percentage of off-target fasting glucose measurement, and the results of the Oral Glucose Tolerance Test at three months postpartum, among others. As previously mentioned, we were also limit the generalizability of our conclusions as we were only able to find information pertaining to gestational diabetes SMBG, with a lack of studies regarding $\mathrm{T} 1$ and $\mathrm{T} 2$ diabetes. Unfortunately, we were unable to conduct a meta-analysis as sufficient data was not reported in the included studies (specifically, measures of dispersion) and the available data did not allow us to conduct our own calculation of these values. For this reason, a synthesis without meta-analysis was the next best option to yield standardized results when meta-analysis is not possible. Although synthesis without meta-analysis presents a viable option in the case of incompletely or heterogeneously reported outcomes or effect estimates in individual studies of a systematic review, it is not as statistically powerful as a meta-analysis [25] and the conclusions that can be drawn from our results are limited in this regard.

\section{Conclusions}

The results of our systematic review regarding the effect of mHealth interventions on glycemic control among women with gestational diabetes mellitus revealed non- 
UNDERGRADUATE RESEARCH IN NATURAL AND CLINICAL SCIENCE AND TECHNOLOGY (URNCST) JOURNAL Read more URNCST Journal articles and submit your own today at: https://www.urncst.com

significant results with a certainty of evidence that was low. However, our review was limited given the incomplete reporting of data in the included studies. Other existing literature suggests that mHealth has the potential to positively impact blood glucose control among adults with diabetes. As there is a current scarcity of randomized controlled trials on this topic, additional research is warranted, particularly given the emphasis on virtual healthcare in light of the COVID-19 pandemic.

\section{List of Abbreviations Used}

A1C: glycated hemoglobin A1C

mHealth: Mobile health

\section{Conflicts of Interest}

All author(s) declare that they have no conflict of interests.

\section{Ethics Approval and/or Participant Consent}

As this systematic review only included publicly available studies, we did not seek ethics approval.

\section{Authors' Contributions}

TR: made substantial contributions to the design of the study, collected, analysed, and interpreted the data, drafted the manuscript, revised the manuscript critically and gave final approval of the version to be published.

HA: made substantial contributions to the design of the study, collected, analysed, and interpreted the data, drafted the manuscript, revised the manuscript critically and gave final approval of the version to be published.

\section{Acknowledgements}

We would like to extend our sincerest gratitude to Katelyn Sushko, without whom this paper would not be possible. She provided her guidance and understanding during this entire process and this work is a testament to her abilities as a mentor. We greatly appreciate everything that she did for us during the process of this paper. Thank you Kate!

\section{Funding}

This study was not funded.

\section{References}

[1] Feig DS, Berger H, Donovan L, Godbout A, Kader T, Keely E, Sanghera R. Diabetes and Pregnancy. Can J Diabetes. 2018;42(3):S255-82. https://doi.org/10.1016/j.jcjd.2017.10.038

[2] CEMACH. Pregnancy in women with type 1 and type 2 diabetes in 2002-03, England, Wales and Northern Ireland. London, UK: Confidential Enquiry into Maternal and Child Health (CEMACH), 2005 http://www.bathdiabetes.org/resources/254.pdf

[3] Feig DS, Razzaq A, Sykora K, Hux JE, Anderson GM. Trends in deliveries, prenatal care, and obstetrical complications in women with pregestational diabetes: a population-based study in Ontario, Canada, 1996-2001.
Diabetes care. 2006 Feb 1;29(2):232-5. https://doi.org/10.2337/diacare.29.02.06.dc05-1482

[4] Feig DS, Hwee J, Shah BR, et al. Trends in incidence of diabetes in pregnancy and serious perinatal outcomes: A large, population-based study in Ontario, Canada, 1996-2010. Diabetes Care. 2014;37:1590-6. https://doi.org/10.2337/dc13-2717

[5] Holman N, Bell R, Murphy H, Maresh M. Women with pre- gestational diabetes have a higher risk of stillbirth at all gestations after 32 weeks. Diabetic medicine. 2014 Sep;31(9):1129-32. https://doi.org/10.1111/dme.12502

[6] Macintosh MC, Fleming KM, Bailey JA, Doyle P, Modder J, Acolet D, Golightly S, Miller A. Perinatal mortality and congenital anomalies in babies of women with type 1 or type 2 diabetes in England, Wales, and Northern Ireland: population based study. Bmj. 2006 Jul20;333(7560):177. https://doi.org/10.1136/bmj.385 6.692986.AE

[7] Inkster ME, Fahey TP, Donnan PT, Leese GP, Mires GJ, Murphy DJ. Poor glycated haemoglobin control and adverse pregnancy outcomes in type 1 and type 2 diabetes mellitus: systematic review of observational studies. BMC pregnancy and childbirth. 2006 Dec;6(1):1-3. https://doi.org/10.1186/1471-2393-6-30

[8] Tennant PW, Glinianaia SV, Bilous RW, Rankin J, Bell R. Pre-existing diabetes, maternal glycated haemoglobin, and the risks of fetal and infant death: a population-based study. Diabetologia. 2014 Feb;57(2):285-94. https://doi.org/10.1007/s00125-0133108-5

[9] American Diabetes Association. 14. Management of Diabetes in Pregnancy: Standards of Medical Care in Diabetes - 2019. Diabetes Care 2019 Jan; 42(Supplement 1): S165-S172. https://doi.org/10.2337/ dc19-S014

[10] Diabetes in pregnancy: management from preconception to the postnatal period NICE guideline [NG3] Published date: 25 February 2015. Last updated: 16 December 2020.

[11] Rudland VL, Price SA, Hughes R, Barrett HL Lagstrom J, Porter C, Britten FL, Glastras S, Fulcher I, Wein P, Simmons D. ADIPS 2020 guideline for preexisting diabetes and pregnancy. Australian and New Zealand Journal of Obstetrics and Gynaecology. 2020 Dec;60(6):E18-52. https://doi.org/10.1111/ajo.13265

[12] Nankervis A, Price S, Conn J. Gestational diabetes mellitus: A pragmatic approach to diagnosis and management. Australian journal of general practice. 2018 Jul;47(7):445. https://doi.org/10.31128/AJGP-01$18-4479$

[13] Alexopoulos AS, Blair R, Peters AL. Management of preexisting diabetes in pregnancy: a review. Jama. 2019 May 14;321(18):1811-9. https://doi.org/ $\underline{10.1001 / j a m a .2019 .4981}$ 
UNDERGRADUATE RESEARCH IN NATURAL AND CLINICAL SCIENCE AND TECHNOLOGY (URNCST) JOURNAL Read more URNCST Journal articles and submit your own today at: https://www.urncst.com

[14] Guerci B, Drouin P, Grange V, Bougneres P, Fontaine P, Kerlan V, Passa P, Thivolet C, Vialettes B, Charbonnel B, ASIA Group. Self-monitoring of blood glucose significantly improves metabolic control in patients with type 2 diabetes mellitus: the AutoSurveillance Intervention Active (ASIA) study. Diabetes \& metabolism. 2003 Dec 1;29(6):587-94. https://doi.org/10.1016/S1262-3636(07)70073-3

[15] Bergenstal RM, Gavin III JR. The role of selfmonitoring of blood glucose in the care of people with diabetes: report of a global consensus conference. The American journal of medicine. 2005 Sep 1;118(9):1-6. https://doi.org/10.1016/j.amjmed.2005.07.055

[16] Franciosi M, Pellegrini F, De Berardis G, Belfiglio M, Cavaliere D, Di Nardo B, Greenfield S, Kaplan SH, Sacco M, Tognoni G, Valentini M. The impact of blood glucose self-monitoring on metabolic control and quality of life in type 2 diabetic patients: an urgent need for better educational strategies. Diabetes care. 2001 Nov 1;24(11):1870-7. https://doi.org/10.2337/diacare.24.11.1870

[17] Hicks J, Muller M, Panteghini M, Garry J. Consensus statement on the worldwide standardization of the hemoglobin A1C measurement: the American Diabetes Association, European Association for the Study of Diabetes, International Federation of Clinical Chemistry and Laboratory Medicine, and the International Diabetes Federation. Diabetes Care. 2007 Sep 1;30(9):2399. https://doi.org/10.2337/dc07-9925

[18] Sheppard P, Bending JJ, Huber JW. Pre- and postprandial capillary glucose self- monitoring achieves better glycaemic control than pre- prandial only monitoring: A study in insulin treated diabetic patients. Practical Diabetes International. 2005 Jan;22(1):15-22. https://doi.org/10.1002/pdi.733

[19] Murata GH, Shah JH, Hoffman RM, Wendel CS, Adam KD, Solvas PA, Bokhari SU, Duckworth WC. Intensified blood glucose monitoring improves glycemic control in stable, insulin-treated veterans with type 2 diabetes: The Diabetes Outcomes in Veterans Study (DOVES). Diabetes care. 2003 Jun 1;26(6):1759-63. https://doi.org/10.2337/diacare.26.6.1759

[20] Negrato CA, Zajdenverg L. Self-monitoring of blood glucose during pregnancy: indications and limitations. Diabetology \& metabolic syndrome. 2012 Dec;4(1):15. https://doi.org/10.1186/1758-5996-4-54

[21] Ventola CL. Mobile devices and apps for health care professionals uses and benefits. Pharmacy and Therapeutics. 2014 May;39(5):356. https://www.ncbi.nlm.nih.gov/pmc/articles/PMC40291 26/

[22] Steinhubl SR, Muse ED, Topol EJ. Can mobile health technologies transform health care?. Jama. 2013 Dec 11;310(22):2395-6. https://doi.org/10.1001/jama.2013 .$\underline{.281078}$

Ricci et al. | URNCST Journal (2021): Volume 5, Issue 5

DOI Link: https://doi.org/10.26685/urnest.218
[23] Wang Y, Min J, Khuri J, Xue H, Xie B, Kaminsky LA, Cheskin LJ. Effectiveness of mobile health interventions on diabetes and obesity treatment and management: systematic review of systematic reviews. JMIR mHealth and uHealth. 2020 Apr 28;8(4):e15400. https://doi.org/10.2196/15400.

[24] Higgins JP, Thomas J, Chandler J, Cumpston M, Li T, Page MJ, Welch VA, editors. Cochrane handbook for systematic reviews of interventions. John Wiley \& Sons; 2019 Sep 23. www.training.cochrane.org/handbook.

[25] Campbell M, McKenzie JE, Sowden A, Katikireddi SV, Brennan SE, Ellis S, Hartmann-Boyce J, Ryan R, Shepperd S, Thomas J, Welch V. Synthesis without meta-analysis (SWiM) in systematic reviews: reporting guideline. bmj. 2020 Jan 16;368. https://doi.org/ $10.1136 / \mathrm{bmj} .16890$

[26] Moher D, Liberati A, Tetzlaff J, Altman DG, Prisma Group. Preferred reporting items for systematic reviews and meta-analyses: the PRISMA statement. PLoS medicine. 2009 Jul 21;6(7):e1000097. https://doi.org/10.1371/journal.pmed.1000097

[27] Hoffmann TC, Glasziou PP, Boutron I, Milne R, Perera R, Moher D, Altman DG, Barbour V, Macdonald H, Johnston M, Lamb SE. Better reporting of interventions: template for intervention description and replication (TIDieR) checklist and guide. Bmj. 2014 Mar 7;348. https://doi.org/10.1136/bmj.g1687

[28] Sterne JA, Savović J, Page MJ, Elbers RG, Blencowe NS, Boutron I, Cates CJ, Cheng HY, Corbett MS, Eldridge SM, Emberson JR. RoB 2: a revised tool for assessing risk of bias in randomised trials. bmj. 2019 Aug 28;366. https://doi.org/10.1136/bmj.14898

[29] Schünemann H, Brożek J, Guyatt G, Oxman A (editors). GRADE handbook for grading quality of evidence and strength of recommendations. Updated October 2013. The GRADE Working Group, 2013.

[30] Borgen I, Småstuen MC, Jacobsen AF, GarnweidnerHolme LM, Fayyad S, Noll J, et al. Effect of the Pregnant+ smartphone application in women with gestational diabetes mellitus: a randomised controlled trial in Norway. BMJ Open. 2019 Nov;9(11):e030884. http://dx.doi.org/10.1136/bmjopen-2019-030884

[31] Guo H, Zhang Y, Li P, Zhou P, Chen LM, Li SY. Evaluating the effects of mobile health intervention on weight management, glycemic control and pregnancy outcomes in patients with gestational diabetes mellitus. J Endocrinol Invest. 2019 Jun;42(6):709-714. https://doi.org/10.1007/s40618-018-0975-0

[32] Miremberg H, Ben-Ari T, Betzer T, Raphaeli H, Gasnier $\mathrm{R}$, Barda $\mathrm{G}$, et al. The impact of a daily smartphonebased feedback system among women with gestational diabetes on compliance, glycemic control, satisfaction, and pregnancy outcome: a randomized controlled trial. Am J Obstet Gynecol. 2018 Apr;218(4):453.e1-453.e7. https://doi.org/10.1016/j.ajog.2018.01.044 
UNDERGRADUATE RESEARCH IN NATURAL AND CLINICAL SCIENCE AND TECHNOLOGY (URNCST) JOURNAL Read more URNCST Journal articles and submit your own today at: https://www.urncst.com

[33] Mackillop L, Hirst JE, Bartlett KJ, Birks JS, Clifton L, Farmer AJ et al. Comparing the efficacy of a mobile phone-based blood glucose management system with standard clinic care in women with gestational diabetes: randomized controlled trial. JMIR Mhealth Uhealth. 2018 Mar 20;6(3):e71. http://dx.doi.org/ 10.2196/mhealth. 9512

[34] Drahota A, Beller E. RevMan Calculator [Internet]. Cochrane Training; n.d [Cited 2020 Oct 16] Available from: https://training.cochrane.org/resource/revmancalculator

[35] Cochrane Effective Practice and Organisation of Care (EPOC). EPOC worksheets for preparing a summary of findings (SoF) table using GRADEn [Internet]. EPOC Resources for review authors; 2017 [Cited 2020 Oct 20] Available from: epoc.cochrane.org/resources/epocresources-review-authors

[36] Murad MH, Mustafa RA, Schünemann HJ, Sultan S, Santesso N. Rating the certainty in evidence in the absence of a single estimate of effect. Evid Based Med. 2017 Mar;22(3):85-87. http://dx.doi.org/10.1136/ebmed -2017-110668

[37] Kitsiou S, Paré G, Jaana M, Gerber B. Effectiveness of mHealth interventions for patients with diabetes: an overview of systematic reviews. PLoS One. 2017 Mar 1;12(3):e0173160. https://doi.org/10.1371/journal.pone .0173160

[38] Collier JL, Fortuin AJ. A review of mHealth interventions for diabetes in pregnancy. Glob. Health Innov. 2019 Nov;2(2). https://doi.org/10.15641/ ghi.v2i2.812

[39] Hall CS, Fottrell E, Wilkinson S, Byass P. Assessing the impact of mHealth interventions in low- and middle-income countries - what has been shown to work? Glob. Health Act. 2014 Oct;7(1). https://doi.org/10.3402/gha.v7.25606

\author{
Article Information \\ Managing Editor: Jeremy Y. Ng \\ Peer Reviewers: Katelyn Sushko, Peter Cahill \\ Article Dates: Received Nov 12 20; Accepted Mar 03 21; Published May 0721
}

\title{
Citation
}

Please cite this article as follows:

Ricci TA, Akbar HA. Effect of mHealth on blood glucose control in pregnancies complicated by diabetes: A systematic review. URNCST Journal. 2021 May 07: 5(5). https://urncst.com/index.php/urncst/article/view/218

DOI Link: https://doi.org/10.26685/urncst.218

\section{Copyright}

(C) Taylor A. Ricci, Husain A. Akbar. (2021). Published first in the Undergraduate Research in Natural and Clinical Science and Technology (URNCST) Journal. This is an open access article distributed under the terms of the Creative Commons Attribution License (https://creativecommons.org/licenses/by/4.0/), which permits unrestricted use, distribution, and reproduction in any medium, provided the original work, first published in the Undergraduate Research in Natural and Clinical Science and Technology (URNCST) Journal, is properly cited. The complete bibliographic information, a link to the original publication on http://www.urncst.com, as well as this copyright and license information must be included.
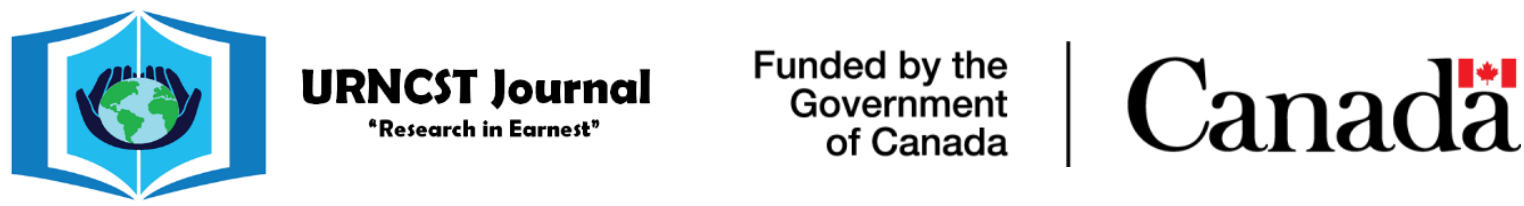
Do you research in earnest? Submit your next undergraduate research article to the URNCST Journal!
| Open Access | Peer-Reviewed | Rapid Turnaround Time | International |
| Broad and Multidisciplinary | Indexed | Innovative | Social Media Promoted |

Pre-submission inquiries? Send us an email at info@ urncst.com | Facebook, Twitter and LinkedIn: @ URNCST

Submit YOUR manuscript today at https://www.urncst.com! 